all the people and all the physicians. Whether I am correct in my vision of this greater service, you alone can show me. Whether to embark on such a plan or not, may be determined by the way you physicians react to it; but should you, by person or letter, show approval I believe the authority and the means can be provided. For the present, such work must be handled by appointment through the hospital office.

In conclusion, I wish to urge that all publie hospitals in Massachusetts adopt a systenı whereby their diagnostic facilities shall become available for all classes of citizens to the end that greater service shall be rendered anil the trend toward greater socialization in medicine shall be guided by the trained intellects in our profession rather than thrust upon us by those unfamiliar with and without svmpathy for the best developments of medical practice.

\section{THE RESIDENT SURGEON AND THE HOSPITAL.}

\section{By Donatd S. adams, M.D., Worchster, Mass.}

THE resident surgeon, or physician for that matter, is not a necessity. There are a number of excellent hospitals in this country where such an office has not been established and yet their standards are high and their reputation the best. To conform with the rerequirements laid down by the American College of Surgeons, a resident is not a requisite. But in spite of this fact, the man who makes good as resident becomes an asset rather than a mere addition to the administrative force.

What are the qualifications of a resident? He should be a graduate of a recognized medical school and hospital and at the latter he would best have had a general service. The single man is the better, for a resident must live at the hospital and be prepared to put his undivided attention into the work laid down for him. And, above all things, he must be ambitious and wide awake, for the opportunities of slacking up and entering a rut make their frequent appearance.

$\mathrm{He}$ comes in constant contact with three forces that always present themselves within the four walls of a hospital, namely the administrative force, the staff, and the house officers. With the former he must, to a certain extent, consider himself a part, and therefore make himself familiar with the rules of the hospital, observe them and be willing to help th when called upon. Make the superintendent feel that you have an interest in your institution and desire to see it advance. A valuable ally may thereby be obtained. His position in regard to the hospital staff is a peculiar one. Although not a member of the staff, he still is closely related to that body and their proceedings must be of vital interest to him. It is best to move slowly at first, noting each man's peculiarities, and then enter into things as the proper time arrives. Their confidence may be obtained and held by an evidence of his desire to fulfill all duties faithfully. And lastly, the house officers. The resident is supervisor of house officers and directly responsible for their work. So he must gain their confidence as well, teach them all he can, get some operative work for them and personally assist them, all with the understanding that they must perform their duties thoroughly. He should instil into their minds the fact that their appointment is to their sole advantage, and off-duty time must be considered only when all work is completed and they can be of no further assistance to the staff. It is also his duty to straighten out any misunderstandings that may arise among them. It might be well to state here that it is an established fact that the first resident in an institution meets with a certain degree of antipathy from the existing house officer regime and cannot hold the controlling hand until they have passed on.

The duties of the resident are not the same in any two hospitals. Thus, in a hospital of 200 beds or under, a man should be able to keep in touch with the proceedings of all the services, including medical, surgical and obstetrical. In the larger hospitals, a staff of residents are required. But it is of the firstmentioned type of institution that I desire to talk. Memorial Hospital has 200 beds, and the resident makes rounds twice a day, morning and evening. Medical and obstetrical cases are studied by him only when a member of the staff asks him to, in case of emergency, or to help the house officers in charge. He thereby has a working knowledge of the cases on hand. At the same time, records are inspected. to see that the routines are being carried out, that the histories and four day notes are up to date, and provisional diagnoses written. The surgical side are supposed to have made their provisional diagnosis by the end of $2-\mathbf{i}$ hours after admission, and the medical side 
are allowed 48 hours. On certain nights, the / resident to apply splints and casts and at the resident and house officers inspect charts to- same time study x-rays. As the members of gether, and in addition, the surgeon-in-chief the staff see he is in earnest and is capable, looks over all the charts with the resident. In they give to him operations of more major this way the paper work is kept up to date.

Discharge cards may be signed by the resident and care is taken by him to see that they are properly filled out and classified.

Each night the resident books the operations to be done the following day. He lists the type of operation, patient's ward and the operator's name with the time he is to operate. One copy is placed on a bulletin board on the wall of the administration building and another on the same kind of a board in the staff room of the surgery. The bulletin boards not only serve that purpose but, in addition, are used for the posting of notices and slips for the members of the staff, calling their attention to the fact that they are wanted in consultation. These slips are dated and the resident watches this board, and when a man does not take down his slip his attention is again called to it. In this way, a perfect record for the filling of consultation requests has been obtained.

The staff meets each Saturday noon and the surgeon-in-chief acts as chairman, and the resident records in a book the proceedings an 1 attendance. At these meetings the mortalities of the preceding week and any business of interest to the staff are discussed.

The nursing faculty may call on the resident, if they see fit, to care for the nurses when they are ill.

The advantage of a residency to a young man are manifold. Alone, the opportunity of working with the surgeon-in-chief and caring for his cases is more valuable than any other training. To assist an experienced man, talk with him, and watch his methods of procedure, are worth years of ordinary hospital work or inexperienced practice.

The opportunity to assist the other surgeons gives the resident a chance to see others operate, and at the same time improve in his own technique. Many dressings may be done on the wards and among such private cases as the man in charge of the cases sees fit to turn over. This is no small item, for the aftercare of cases and their dressings are of vast importance. Emergency work, including fractures and dislocations, offer a chance for the character until the resident is getting his share of the ward operating, which is as much as any young man could ask for.

And lastly, the question of financial remuneration comes up. The salary of a resideut varies in different institutions, from five hundred to fifteen hundred dollars a year, together with his living expenses. To the man who plans to enter private practice later on, this income, put away in the bank, will be highly appreciated.

In conclusion I would like to consider what the resident may do to help maintain the hospital standards. I have already mentioned his care of the charts, attempts to see that the consultation requests are filled, operations booked in such an order that friction is avoided, and general supervision over the house officers. One more point remains, namely, the care of the monthly hospital analysis. In Memorial Hos pital, every attempt is made to live up to the American College of Surgeons standards. Dr. Homer Gage, Surgeon-in-Chief, planned a monthly report or analysis of the hospital services, using a modification of the one designed by the College. He calls upon the resident to analyze the cases each month and when the report is completed, he reads it at staff meeting, and an interesting discussion follows. There is no better way of bringing up before the staff a review of the preceding month. It is an excellent opportunity for the resident to go over the records, admission and discharge cards aud end results cards. When it is complete, the following points have been ascertained:

1. Number of acute abdominal cases entering hospital, with the diagnosis, name of operator, time between admission and onset, and time between admission and operation.

2. Number of admissions to hospital. Number discharged cured, relieved, and dead.

3. Consultations: number asked and obtained, asked and not obtained, and finally indicated and not asked.

4. Diagnosis: number of provisional and final diagnoses that agree, number that disagree. Number of cases discharged with no diagnosis, and number of those discharged with added diagnosis. 
5. Institutional infections-medical, surgical and obstetrical, giving the type of infection, name of attendant and ward. This brings out the occurrence of stitch abscesses, post-partum infections and contagious diseases.

6. An itemized list of the cases discharged unimproved, with the name of the attendant and the number of days patient was in the hospital.

7. Average number of days of discharged patients. Number of those staying in the hospital more than three weeks, and number of patients now in the hospital more than one month.

8. Itemized list of the causes of death.

9. Number of deaths on (a) Medical Service, (b) Surgical Service, and (c) Obsterical Service. Also the number of autopsies obtained on these services.

10. Analysis of obstetrical services, showing the number of normal deliveries performed by each obstetrician and then in turn the number of instrumental deliveries each man resorted to. Obstetrical complications are noted, with their treatment and the ultimate result obtained.

11. List of Caesarean sections performed, with name of operator, assistant, ward, and indication for so doing.

12. Those cases discharged with no diagnosis, giving the name of the attendant and his reason for not arriving at some diagnosis.

Considering the various points brought out in this paper, it is fair to assume that a residency is worth any man's time. By conscientious work and following the guide of a competent surgeon-in-chief, he may be of real value to the hospital.

EXTRAPLEURAL RESECTION AND PLASTIC OF THE THORACIC ESOPHAGUS. AN ORIGINAL METHOD. REPORT OF SUCCESSFUL CASE WITHOUT GASTROSTOMY:

Bx Howard Lminenthat, M.D., F.A.C.S., New York. Author's Abstract.

This operation was devised to minimize the danger of septic mediastinitis. It was recognized that before opening the esophagus the mediastinum must be sealed off by a healing process which should have advanced to the stage of granulation.

* Read before the American Surgical Society, at its meeting in June, 1921, in Toronto. To be published in full in The Annals of :Sungery.
The yatient was a 35-year-old man with a partially abstructing squamous cell carcinoma below the arch of the aorta. At the first step, the operator lifted skin flap about three inches in width and 10 inches in length which was outlined by an incision beginning at the eighth interspace close to the spine, passing obliquely forward parallel to the ribs, thence downward and then backward to a point about three inches below the place of beginning. This flap was used in fashioning the new esoyhagus to take the place of the resected part. A six-inch subperiosteal resection of the ninth rib was then made and the pleura stripped forward away from the posterior mediastinal region. The eighth, seventh and sixth ribs were cut through near their spinal attachments after peeling the pleura away and then the tenth rib also was divided. The pleura could now be pushed forward, exposing the organs within the mediastinum through a wound large enough to permit the surgeon to work with both hands in its depths. With a stomach tube in the esophagus, this structure was easily identified and stripped from the pleura and aorta. The fibers of the plexus gulae of the right vagus wers; devided. The fusiform swelling which marked the tumor within the gullet was about an inch and a half below the arch of the aorta. The skin flap whs p!aced in to wound so that it partly encircled the mobilized esophagus, the cutaneous surface toward the viscus. This first step of the operation was coneluded by packing the wound with gauze. The patient could swallow fluids. Two weeks later, without anaesthesia of any kind, the wound was spread apart and the tumor-bearing section of the esophagus was resected. Nourishment was now given through a stomach tube passed into the lower esophageal opening and later through an Einhorn tube passed from mouth to stomach through the gap left by the resection. The pedicle of the skin flap was cut across in another week. There was later contraction of the cicatricial tissue at the mucreutaneous margins, making it necessary to divide the strictures by stellate incisions and thereafter: bougies were passed frequently. The final step was to close the posterior esophageal opening by suture and to make a plastic operation to cover the defect. in the patient's back with skin by the use of sliding, flaps. A few days after this final procedure, liquids conld be swallowed without leakage, and soon all wounds were healed and any soft food could be taken normally.

A number of drawings were made at the operation and are reproduced in the article. There are also roentgenograms and a photograph.

Other cases in which this exposure was made are reported but all proved inoperable. The conclusions are as follows:

1. That transpleural resection of the esophagus has a forbidding mortality.

2. That fatal infection follows the primary opening of the esophagus within the mediastinum.

3. That it is feasible to make an extrapleural exposure of the posterior mediastinum large enough to jermit the operator to see clearly and to work safely with both hands.

4. That resection of the esophagus in the posterior mediastinum can be done by dividing the operation into two stages. At the first, the esophagus is freed from its attachments and the mediastinum is sealed. At the second, 10 to 14 days later, the resection is performed.

5. This procedure deserves a fair trial by thoracic surgeons. 